\title{
Empirical analysis of Cognitive bias in Behavioral Finance Model
}

\author{
Seong-hoon Jeong ${ }^{1}$, In-ho Choi ${ }^{2}$ \\ ${ }^{1}$ Associate professor in Dept. of Economics \&amp; International Trade, Catholic \\ University of Daegu, Daegu city, 384-30, South Korea, \\ ${ }^{2}$ professor in Dept. of Real Estate, Namseoul University, Cheonan city, 331-707, \\ South Korea \\ 1James1101@cu.ac.kr, ${ }^{2}$ landchoi@nsu.ac.kr
}

\begin{abstract}
The purpose of this study is to analyze the cognitive bias of real estate investors using the maximized potential rate of profit model, the maximized potential rate of loss model, the gain of a real estate model and the loss of real estate model and verified the effect of tax policy on investor's cognitive bias. This study used PRMR-LPMR model which is a frequency model which are used for the potential profit and the loss rate. The result of the study were rejected in the first and second increase of transfer income tax and a second increase of acquisition tax.

Keywords: Acquisition Tax, Transfer Income Tax, Potential Rate of Profit Model, Gain of A Real Estate Model, Loss of Real Estate Model, Tax Policy, PRMR-LRMR Model.

\section{Introduction}

The Prospect theory investigated by Kahneman and Tversky (1979) is an important theoretical mechanism explaining the disposition effect and the various cognitive biases[1]. For example, if a real estate shows a loss, the investors who own the real estate would hold it because of the loss aversion. Meanwhile, if a real estate shows a profit, the investors realize profit if there is no special event, follows an $\mathrm{S}$ shape maximizing the utility function, which is suggested by Kahneman and Tversky[2].

This investment behavior is not rational because each section has different risk preferences, which can trigger the investors' instinct [12]. Therefore, this study accepts the prospect theory as a theoretical mechanism to investigate the cognitive bias of the investors. Also, it investigates the change of investors' cognitive bias depending on the change of tax policy using the maximized potential rate of profit model, the maximized potential rate of loss model, the gain of a real estate model, and the loss of real estate model[3].
\end{abstract}

\section{PRMR and LRMR Model}

Frequency of profit and loss compare model, which are previously described, are possible to analyze investment performance sorted by the frequency [13]. Although investors could get more profit, there is nothing shows whether the investors realized profit quickly or investor showed the appropriate reaction to loss [4]. So, this study analyzes the performance of the

Article history:

Received (April 19, 2019), Review Result (May 21, 2019), Accepted (July 29, 2019) 
investor's decision using PRMR and LRMR model; PRMR is profit real estate maximized potential rate of profit[5], LRMR is loss real estate maximized potential rate of loss [6].

This model analyzes the added potential profit or loss when an investor does not realize profit or loss [7]. Before using this model, this paper grasped the maximized potential profit and the maximized potential loss. Although in the stock market, it is easy to find out some stock's maximized potential profit or maximized potential loss because of stock price data of everyday are existing in the market [8].

In case of real estate market it is hard to see maximized potential profit or maximized potential loss[9]. Since this model needs the price of real estate to work[10], this paper uses the land price of the area as a proxy.

$$
\begin{aligned}
& \text { PRMR }=\sum_{t=1}^{n} \frac{M P R P}{R R P+M P R P} \\
& \mathrm{LRMR}=\sum_{t=1}^{n} \frac{M P R L}{R R L+M P R L}
\end{aligned}
$$

PRMR: Profit Real Estate Maximized Potential Rate of Profit

LRMR: Loss Real Estate Maximized Potential Rate of Loss

MPRP: Maximized Potential Rate of Profit in Real Estate Price Index

MPRL: Maximized Potential Rate of Loss in Real Estate Price Index

RRP: Realized Rate of Profit

RRL: Realized Rate of Loss

$\mathrm{H}=\frac{12}{n(n+1)} \sum \frac{T_{i}^{2}}{n_{i}}-3(n+1)$

T i : Rank sum of i group

n i : Number of group

This method verifies the null hypothesis, "samples are same", is rejected or not, through measuring approximate significance probability using the calculated chi squared from statistical value $\mathrm{H}[11]$.

\section{The hypothesis for research}

[Hypothesis 5]: PRMR; Profit Real estate Maximized potential Rate of Profit is larger than LRMR; Loss Real estate Maximized potential Rate of Loss 
[Hypothesis 5-1]: If the acquisition is increased, the difference between PRMR and LRMR is expanded.

[Hypothesis 5-2]: If the transfer income tax is increased, the difference between PRMR and LRMR is expanded

\section{Analysis of PRMR and LRMR according to increase tax rates}

The result of examining the psychology of real estate investors using PRMR of profit real estate and LRMR of loss real estate says that the investors of real estate can earn a potential profit. Moreover the LRMR increased more than before a tax rate increase in loss real estate, which is estimated that the investors sold it before they have a big loss.

These results show that after the increase of tax rate, investors' investment behavior would be more desirable. First of all, in 6 month analysis, PRMR at the time of increasing of transfer income tax was calculated at 0.2 .

However, after the implementation, PRMR was 0.128. It suggests that after the increase, the investors show more desirable investment behavior than before. It is because the investors who sold their property before tax rate increase did not get their potential profit because they reacted urgently to a negative signal such as increase tax rate. In case of loss real estate investors, they also had a loss which was preventable because they reacted risk-averse to the negative signal. Next, the PRMR value before the increase is 0.246 , but PRMR after the increase is 0.134 during the period of increase of second transfer income tax analysis. It means that investors got more potential profit than before the increase because of the increase of acquisition tax and transfer income tax.

As I mentioned above, it is because the investors sold their property urgently because they reacted to increase the tax rate negatively. And, after the increase, the investment behavior was more preferable than before because they trade it more carefully for incidence of taxation. It means that it rejected the hypothesis. Before the increase of transfer income tax, investors do not show a desirable investment behavior.

However, they made more preferable investment behavior after the increase. January 1, 2013, the start of second increase of acquisition tax, PRMR before the implementation was 0.172 , after the implementation PRMR was 0.142. It is confirmed that investors traded more carefully before the increase because the investors feel pressure from the increase of acquisition. Loss investors' LRMR raises from 0.005 to 0.006 during before and after the increase, potential loss would be bigger than before so investors did trade more carefully. It suggests that the increase of acquisition tax is influenced on the investors' careful trade.

However, the increase of July 1, 2013, the third increase period, was different; PRMR (0.146) rises as 0.166 after the increase. It could be considered that the increase of acquisition tax in July 1, 2013 did not influence on the investors because of the 8.28 plan which was announced in August 28, 2013. Unlikely previous increase policy, the third increase, which was temporal, made investors who had profit real estate sell their property quickly due to the uncertainty of policy which was shifting frequently.

But, it is good for the investors who had loss real estate because they sold their property quickly to prevent a potential loss. It is interpreted that if the change of policy occurs often, investors sold their property quickly because of the anxiety.

The result accepts the hypothesis in third increase, but rejects it in the result of first and second transfer income tax increase and second acquisition tax increase. This result is similar to PRMR-LRMR which was an analysis of 1 year period, but there is a different outcome in third acquisition tax increase period analysis. 
First of all, PRMR before the third acquisition tax increase was 0.225 . But, after the increase, PRMR was 0.117. It is adverse to the six month analysis. In addition, hypothesis is rejected because LRMR goes up from 0.009 to 0.018 after the increase. The reason of the difference between 1 year analysis and 6 month analysis is because the permanent reductions of acquisition tax that was implemented in the 8.28 plan after the increase.

This permanent reduction system is fixed in January 2014 and it makes trade safer than before. So, it is more stable than the 6 month analysis, which helps investors' potential profit to decrease.

Table 1. The analysis of PRMR-LRMR when the tax increased

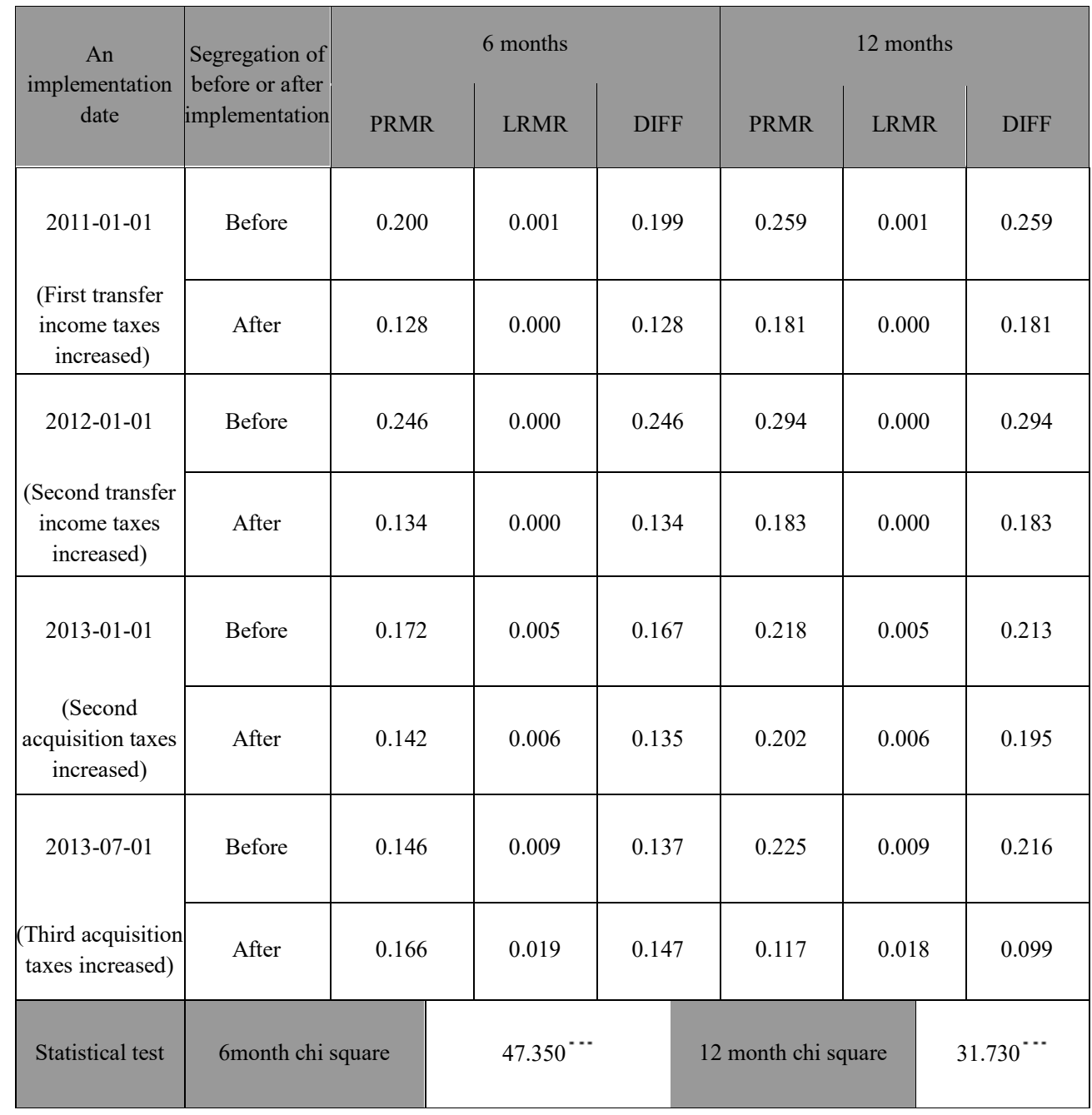

This study uses the 2,245 data through the certificate copy of the registration. The range of analysis is from the - 60 days of tax increase implementation to the 60 days of tax increase implementation. The before means that the range of time when it is from the -60 days before the implementation to -1 days before the implementation. And then after means that the range of time when it is from the 0 days to +60 days. In this data, this study did statistical test which it is definitely the difference between before and after, PRMR or LRMR. 


\footnotetext{
***: Significant level is less than 0.01

**: Significant level is less than 0.05

*: Significant level is less than 0.1
}

\section{Conclusion}

This study examined that cognitive bias of real estate investors using PRMR-LRMR model and investigated how the change of government's tax policy could influence cognitive bias of investors. This study has investigated the real estate investor's cognitive bias and the influence of change of tax policy using 2,245 copies of residence register to solve the data collecting problem. In the previous research, there is no case of using PRMR and LRMR in the real estate market except the stock market. So, this study is different from the former study of real estate investment behavior. It explains whether the investment behavior is appropriate using PRMR and LRMR. In addition, there are academic suggestions; it expends the base of behavior taxation investigate to import the concept of the investment psychology, and it studies about cognitive bias in the real estate market and find out recency prejudiced. And then there is a social suggestion that, cognitive bias could be reduced by using the investment psychology if the tax rate increases as a government tax policy. And if recency prejudice is used, the effect of extend will be better.

This investigate used monthly real estate price of each residence in calculating PRMR and LRMR value. It solves the problem that is no daily trading in real estate. Although this real estate price could confirm the change of each residence, but it is difficult to explain the price change, and it has a limit on the possibility of attenuating data. But the explanatory power is as good as a substitute because there is no daily index of real estate. This limitation should be improved through the further research.

\section{References}

[1] Ayers, Benjamin, C., Cloyd, C. Bryan., Robinson, John, R., "The Effect of Shareholder-Level Dividend Taxes on Stock Prices: Evidence from the Revenue Reconciliation Act of 1993”. The Accounting Review(2002), Vol. 77. No. 4, pp. 933-947

[2] Best, Michael Carlos, Henrik Jacobsen Kleven, \&quot; Housing market responses to transaction taxes: Evidence from notches and stimulus in the UK\&quot(2013), Mimeo, pp.1-46.

[3] Cloyd, C. Bryan, Brian C. Spilker, \&quot;Confirmation bias in tax information search: A comparison of law students and accounting students.\&quot; Journal of the American Taxation Association, 22.2(2000), pp. 60-71

[4] Collins, Julie H., Kemsley, Deen, "Capital Gains and Dividend Taxes in Firm Valuation: Evidence of Triple Taxation.” Accounting Review. Vol. 75 Issue 4, (2000), pp. 405-427

[5] Dai. Zhonglan., Maydew Edward, Shackelford Douglas A., Zhang, Harold H, "Capital Gains Taxes and Asset Prices: Capitalization or Lock-in?\&quot;. The Journal of Finance. Vol. 63 Issue 2(2008), pp. 709-742

[6] Elffers, Henk, Henry SJ Robben, Dick J. Hessing, \&quot;On measuring tax evasion.\&quot; Journal of economic psychology 13.4(1992), pp. 545-567

[7] Engelhardt, Gary V., \&quot;Nominal loss aversion, housing equity constraints, and household mobility: evidence from the United States.\&quot; Journal of Urban Economics, 53.1(2003), pp. 171-195 
[8] Bokhari, Sheharyar, David Geltner, \&quot;Loss aversion and anchoring in commercial real estate pricing: Empirical evidence and price index implications.\&quot; Real Estate Economics 39.4(2011) pp. 635-670

[9] Brzezicka, Justyna, Radosław Wiśniewski., \&quot;Calendar Effects on the Real Estate Market.\&quot; Real Estate Management and Valuation 21.2(2013), pp. 13-21

[10] Colin, Camerer, Loewenstein George, \&quot;Behavioral economics: Past, present, future. Princeton\&quot; Princeton University Press(2004)

[11] Odean, Terrance, "Are individual investors tax savvy? Evidence from retail and discount brokerage ccounts" Journal of Public Economics, 88, (2003), pp. 419-442

[12] Roth, Jeffrey A., John T. Scholz, and D. Witte, eds., Taxpayer compliance: An agenda for research. Vol. 1. University of Pennsylvania Press(1989)

[13] Shefrin, Hersh., "Behavioral corporate finance: Decisions that create value."(2007)

\section{Authors}

\section{Seong-hoon Jeong}

Author's profile : Main author,

Associate professor in Dept. of Economics \&amp; International Trade, Catholic University of Daegu, Daegu city, 384-30, South Korea.

E-mail : James1101@cu.ac.kr

\section{In-ho Choi}

Corresponding author

professor in Dept. of Real Estate, Namseoul University, Cheonan city, 331-707, South Korea, E-mail :landchoi@nsu.ac.kr 